\title{
Prevalence and Predictive Value of Hypoalbuminemia in Appalachians With Chronic Kidney Disease
}

\author{
Rebecca J. Schmidt ${ }^{\mathrm{a}, \mathrm{c}}$, Bethany Pellegrino ${ }^{\mathrm{a}}$, Karen MacKay ${ }^{\mathrm{a}}$, Tony Parravani ${ }^{\mathrm{a}}$, \\ Raza Mustafa ${ }^{a}$, Gerry Hobbs ${ }^{\mathrm{b}}$
}

\begin{abstract}
Background: Chronic kidney disease (CKD) has reached epidemic proportions worldwide and in the United States, racial minorities reach end stage renal disease (ESRD) at a disproportionate rate. A rural state in the heart of Appalachia, West Virginia leads the nation in rates of incident ESRD, despite its predominantly Caucasian population. Characteristics of this racially homogeneous CKD population are herein examined for their impact on progression to ESRD or death.
\end{abstract}

Methods: Retrospective analysis of demographic and clinical information for 4258 patients seen between 2001 and 2010. Associations between risk factors and outcomes were assessed for significance using Cox Proportional Hazards models.

Results: Patients with CKD were largely Caucasian (94.3\%), 39\% diabetic, with a mean age of $60.1 \pm 16.7 ; 39 \%$ presented with serum albumin levels $\leq 3.5 \mathrm{~g} / \mathrm{dl}$. Patients with higher albumin levels had better survival and less progression to dialysis than those with lower levels ( $\mathrm{P}<0.0001)$. Hypoalbuminemia, hypocalcemia,

Manuscript accepted for publication October 21, 2011

${ }^{a}$ Department of Medicine Section of Nephrology, West Virginia University School of Medicine, Morgantown, West Virginia 26506, USA

${ }^{\mathrm{b}}$ Department of Statistics and Community Medicine, West Virginia University School of Medicine, Morgantown, West Virginia 26506, USA

${ }^{c}$ Corresponding author: Rebecca J. Schmidt, Section of Nephrology, Department of Medicine, West Virginia University School of Medicine, One Medical Center Drive, Box 9165, Morgantown, West Virginia 26506, USA. Email: rschmidt@hsc.wvu.edu

doi:10.4021/wjnu3e hyperparathyroidism and anemia independently correlated with reduced survival and more rapid progression to ESRD $(\mathrm{P}<0.0001)$. Compared to those from more affluent counties, patients from poorer counties had lower albumin levels $(3.36 \pm 0.014$ vs $3.68 \pm 0.079$ $\mathrm{gm} / \mathrm{dl} ; \mathrm{P}<0.04)$ and higher rates of progression to dialysis or death $(\mathrm{P}<0.016)$.

Conclusions: In this predominantly Caucasian population of central Appalachia, hypoalbuminemia and residence in a county of low socioeconomic status independently predicted overall survival and progression to dialysis, suggesting that poverty and culture, irrespective of race, warrant further study for their impact on outcomes in patients with CKD.

Keywords: Albumin; Chronic kidney disease; Hypoalbuminemia; Socioeconomics; Survival

\section{Introduction}

Chronic kidney disease (CKD) is recognized as a major public health problem, and since 1994, West Virginia has led the United States in numbers of patients per million population starting dialysis because of end stage renal disease (ESRD) (Fig. 1) [1, 2]. In 2007, the incidence and prevalence of CKD among West Virginia Medicare patients was among the highest in the nation, along with 6 other states, 2 of which (Kentucky and Georgia) have counties in Appalachia [2]. In 2007, West Virginia's rate of dialysis starts (434.3 per million population) was 4th highest for incident diabetic ESRD and 10th highest for incident ESRD due to non-diabetic causes [2]. Only 2 other states (Texas at 418.0 and Louisiana at 400.4) had overall incident ESRD rates exceeding 400 per million population with Louisiana being higher in non-diabetic ESRD incidence than West Virginia (228.60 vs. 214.3), but lower for diabetic ESRD incidence (171.5 vs 214.0). Diabetic incident ESRD rates were higher in Texas, New Mexico and Hawaii though these states had less non-diabetic incident ESRD than West Virginia [2]. Challenges associated with CKD in West Virginia include the state's high prevalence of risk factors for CKD, namely, diabetes and hypertension, which are leading causes of kid- 


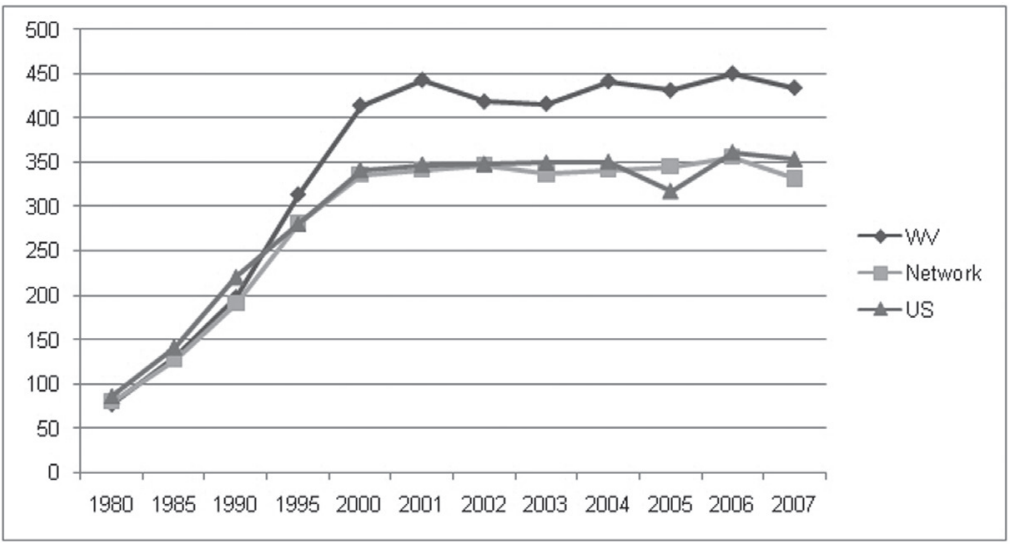

Figure 1. Incidence of ESRD (persons per million population) from 1980 to 2007 for West Virginia, Network 5 and the US [2].

ney disease [3]. Perhaps most curious is the finding that West Virginia has high ESRD rates for both diabetic and non-diabetic patients. Non-diabetic CKD is difficult to quantify and additional factors posing heightened risk for ESRD in West Virginia have yet to be clarified. Further, projections that the ESRD population in the United States will reach 784,000 patients by the year 2020 underscore the need to address regional variations and secondary risk factors for CKD [4]. In this review, the characteristics of patients with CKD in the north central West Virginia region of Appalachia are described and factors associated with progression of CKD to the need for dialysis or death examined.

\section{Materials and Methods}

Demographic information, clinical characteristics and laboratory values were reviewed for 5,408 patients seen by our university nephrology group between January 1, 2000 and July 31, 2010. Patients were seen and evaluated at 1 of 9 facilities, including a main campus CKD clinic and 8 outreach sites ranging from 30 minutes to 2.5 hours. All participants were aged 18 or older and hailed from 1 of 45 West Virginia counties or lived in a county from Maryland or Pennsylvania in close proximity to 1 of the CKD clinics.

Blood and urine studies were done on a serial basis according to CKD stage. Patients underwent phlebotomy and provided urine for analysis at various rural sites in north central West Virginia; results were electronically captured or communicated by telefax for manual entry into a database for CKD patients registered in the clinics. Kidney function as estimated by glomerular filtration rate (eGFR) was calculated for 4,258 patients and 3,091 of these had serum albumin coinciding with their first visit. Results for hemoglobin, parathyroid hormone and calcium levels were available for 2025, 1692 and 2185 patients, respectively. Serial lab values were available for 3,749 patients. Patients were medically managed by 1 of our 5 physicians or 4 nurse practitioners; the majority seen initially by a physician with serial followup by a nurse practitioner.

Census statistics for annual median household income and the percent of residents living below the federal poverty level $(\%<$ FLP) $(\$ 10,827$ and $\$ 18,346$ for an individual and family of 3 , respectively), were ranked for each county of West Virginia [5, 6].

Informed consent for inclusion in the CKD registry was obtained after approval by the Institutional Review Board of West Virginia University.

Baseline characteristics of patients are described using mean values $\pm \mathrm{SD}$ and proportions. Estimates of persons with CKD from the US general population were taken from publicly available data from the National Health and Nutrition Examination Survey (NHANES) 1999 - 2006 [7]. Unpaired $t$ tests were used to compare means and $2 \times 2$ contingency tables to compare categorical data. A P value of $<0.05$ was considered statistically significant.

The significance of associations between individual risk factors and time-to-event (death or start of dialysis) was assessed using Cox Proportional Hazards models. Parameters assessed for risk were each patient's first blood test results for the following: albumin, hemoglobin, serum calcium and parathyroid hormone level. Three economic county-level variables were available for analysis: $\%<$ FPL, annual median household income and percent of high school graduates. A principal component analysis on correlations of the 3 variables showed that the first component captured nearly $83 \%$ of the variation in the set of all 3 . The $\%<$ FPL loaded negatively on the component while the other 2 variables (annual median household income and percent high school graduates) loaded positively on it. We termed the collective representation of these 3 variables the economic index because higher values of the variable indicated counties of residence with more favorable economic values. Economic index served as an additional risk factor. 


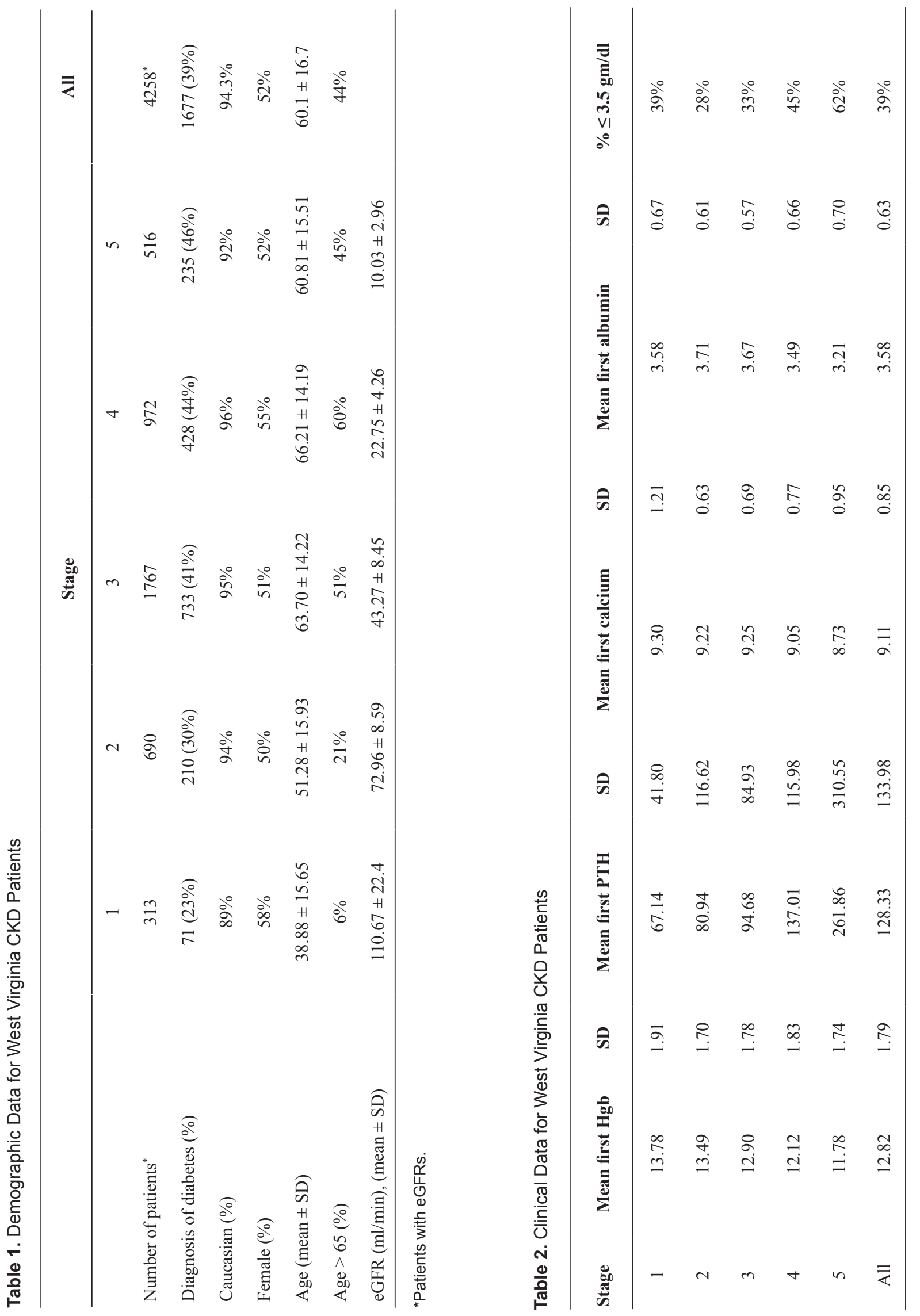


Table 3. Albumin Levels of West Virginia Patients vs. NHANES Dataset [9] and a Large Urban Public Health System [9]

\begin{tabular}{|c|c|c|c|c|}
\hline Stage & $\begin{array}{c}\text { WV CKD } \\
(\text { mean } \pm \text { SE })\end{array}$ & $\begin{array}{l}\text { NHANES CKD } \\
(\text { mean } \pm \text { SE })\end{array}$ & $\begin{array}{c}\text { WV CKD } \\
(\text { mean } \pm \text { SD })\end{array}$ & $\begin{array}{c}\text { Urban Public Health System (mean } \pm \\
\text { SD) }\end{array}$ \\
\hline $3 a$ & $3.67 \pm 0.02$ & $4.2 \pm 0.01$ & $3.67 \pm 0.58$ & $4.0 \pm 0.6$ \\
\hline $3 b$ & $3.67 \pm 0.02$ & $4.1 \pm 0.02$ & $3.67 \pm 0.57 \ddagger$ & $3.7 \pm 0.8 \ddagger$ \\
\hline 4 & $3.49 \pm 0.02$ & $4 \pm 0.04$ & $3.49 \pm 0.66 \dagger$ & $3.4 \pm 0.8 \dagger$ \\
\hline 5 & $3.21 \pm 0.04$ & $4.1 \pm 0.16$ & $3.21 \pm 0.70 *$ & $3.4 \pm 0.7 *$ \\
\hline
\end{tabular}

$P<0.0001$ except where ${ }^{*} P=0.001 ; \uparrow P=0.16 ; \ddagger=N S$.

\section{Results}

Demographic and clinical information for 4,258 patients seen between January 1, 2001 and July 31, 2010 were reviewed and are presented in Tables 1 and Table 2.

Patients were predominantly Caucasian (94.3\%) with a mean age of $60.1 \pm 16.7$ years. The prevalence of African Americans (3.24\%) was significantly lower than that reported in national CKD prevalence estimates $(7.3 \%)$; $(\mathrm{P}$ $<0.0001)$. Nearly half $(1,872$ or $44 \%)$ were older than 65 years of age at diagnosis with Stage 4 CKD having the largest proportion $(60 \%)$ of patients older than 65 years. Women comprised 52 percent of the group overall and were similar in age to men $(60.31 \pm 16.78$ vs. $59.83 \pm 16.5$; mean \pm SD). Diabetes was present in $39 \%$ and the proportion of patients with diabetes increased with declining renal function and later stage.

Mean hemoglobin, parathyroid hormone and serum calcium levels at first presentation were $12.82 \pm 1.79 \mathrm{gm} / \mathrm{dl}$, $128.33 \pm 133.98 \mathrm{pg} / \mathrm{dl}$ and $9.11 \pm 0.85 \mathrm{mg} / \mathrm{dl}$ respectively (mean $\pm \mathrm{SD}$ ) (Table 2). Albumin levels declined with worsening kidney function (increasing stage), ranging from 3.71 \pm 0.61 in patients with mild CKD (Stage 2) to $3.21 \pm 0.36$ in those with severely reduced kidney function (CKD Stage 5). At all stages the mean albumin level was less than 3.8 $\mathrm{gm} / \mathrm{dl}$ with $39 \%$ of patients overall and $33-62 \%$ of patients with Stages 3 - 5, respectively, presenting with albumin levels $\leq 3.5 \mathrm{gm} / \mathrm{dl}$. Albumin levels for Stages 3 - 5 for our patient group are compared with those of national estimates as shown in Table 3 and Figure $2[8,9]$.

Of the entire group, 3,734 (88\%) hailed from 45 West Virginia counties, 38 of which have higher $\%<$ FPL than the national average, with 41 having annual median household incomes below the national average of $\$ 52,029$. Median household income $(\$ 35,895)$ and \% < FPL $(17.6 \%)$ for the CKD group was similar to the state overall $(\$ 37,528$ and 17.4

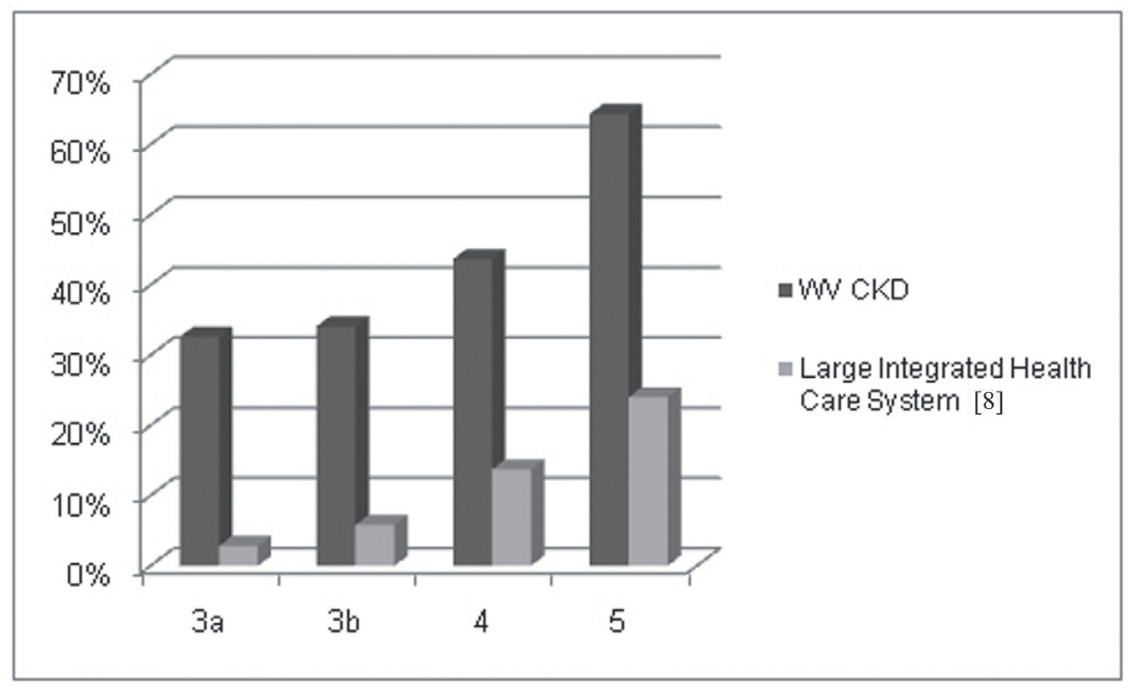

Figure 2. Percent of patients with presenting albumin levels $\leq 3.5 \mathrm{~g} / \mathrm{dl}$. 
Table 4. Albumin and eGFR at Presentation by County Socioeconomic Status and Life Expectancy Rate

\begin{tabular}{|c|c|c|c|c|}
\hline & \multicolumn{2}{|c|}{$\%<\mathbf{F P L}^{\dagger}$} & \multicolumn{2}{|c|}{ Life expectancy rates } \\
\hline & High & Low & High & Low \\
\hline \multirow[t]{2}{*}{$\mathrm{eGFR}(\mathrm{ml} / \mathrm{min})^{*}$} & $49.95 \pm 0.45$ & $43.85 \pm 4.31$ & $41.34 \pm 1.00$ & $46.75 \pm 0.59$ \\
\hline & \multicolumn{2}{|c|}{$\mathrm{P}=0.06$} & \multicolumn{2}{|c|}{$\mathrm{P}<0.0001$} \\
\hline \multirow[t]{2}{*}{$\operatorname{albumin}(\mathrm{g} / \mathrm{dl})^{*}$} & $3.46 \pm 0.01$ & $3.68 \pm 0.08$ & $3.71 \pm 0.22$ & $3.48 \pm 0.01$ \\
\hline & \multicolumn{2}{|c|}{$P=0.04$} & \multicolumn{2}{|c|}{$\mathrm{P}<0.0001$} \\
\hline
\end{tabular}

* Average values at first presentation for West Virginia patients (mean $\pm \mathrm{SE}$ ); † From counties where percent of residents living below the federal poverty level exceeds national average (13.2\%); $\ddagger$ From counties with low life expectancy rates.

percent). The eGFR at presentation for patients from counties with high $\%<$ FPL was higher but not significantly so than that of patients from counties with low $\%<$ FPL; albumin levels at first presentation were significantly lower in the group from counties with high $\%<$ FPL than those patients from counties with low $\%<$ FPL (Table 4). At all stages of eGFR, the majority $(90 \%)$ came from counties where median household income was less than the national average.

Four of West Virginia's 55 counties have life expectancy rates exceeding those of the national median; these counties were represented in our clinics by 783 patients $[10,11]$. Presenting eGFR level of patients from these 4 counties (41.34 $\pm 1.00 \mathrm{ml} / \mathrm{min}$ ) was significantly lower than that of those pa- tients from counties with lower life expectancy rates (46.75 $\pm 0.59 \mathrm{ml} / \mathrm{min}) ; \mathrm{P}<0.0001$. Presenting albumin also differed significantly, with patients from counties with the lowest life expectancy rates having the lowest albumins $(3.71 \pm 0.02$ vs.3.48 \pm 0.13 ) mean $\pm \mathrm{SE}$; $\mathrm{P}<0.0001$ ) (Table 4).

Clinical parameters for the 579 patients who died were similar to those of the overall group except the degree of hypoalbuminemia. Albumin levels of patients who died before starting dialysis were lower than those of patients who survived ( $3.25 \pm 0.72$ vs. $3.62 \pm 0.58 ; \mathrm{P}<0.0001)$. Proportional hazards models showed that patients from counties with higher values of the economic index variable had lower rates of progression to dialysis and better survival than those from
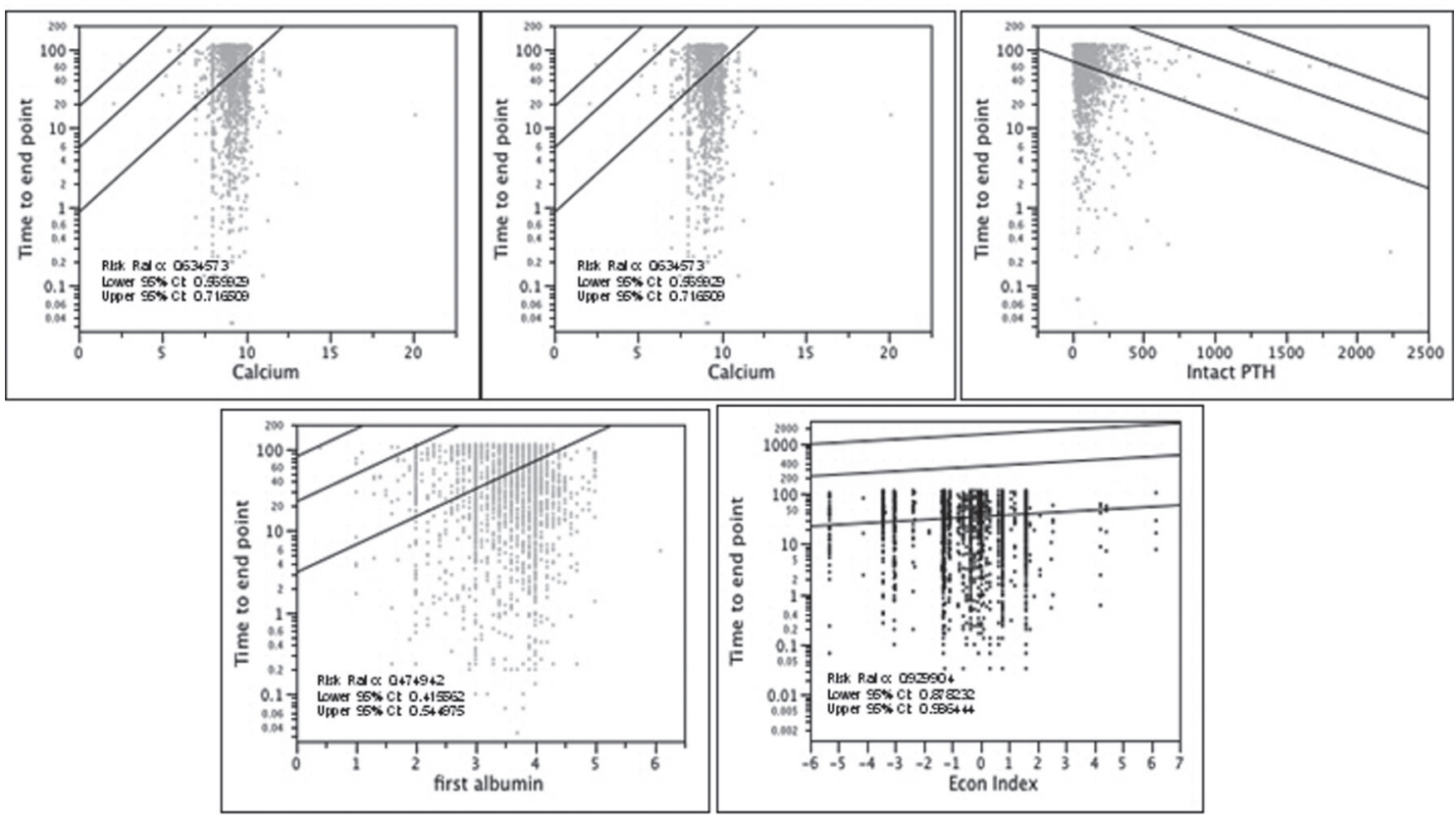

Figure 3. Plot survival quantiles for blood parameters at presentation and time to death or start of dialysis. Curves are fitted 10 th, 50 th and 90th percentiles as a function of calcium, hemoglobin, intact PTH, albumin and economic index. 
poorer counties $(\mathrm{P}=0.0162)$. In addition, patients presenting with higher albumin, higher calcium and higher hemoglobin levels had better survival and less progression to dialysis than those with lower albumin, calcium and hemoglobin levels, respectively $(\mathrm{P}<0.0001)$ (Fig. 3). Patients presenting with higher parathyroid hormone levels had worse survival and faster progression to dialysis than those with lower values $(\mathrm{P}<0.0001)$. Used in a multiple variable Cox Model, the resulting analysis showed significance for albumin $(\mathrm{P}$ $=0.0122)$, parathyroid hormone $(\mathrm{P}=0.0001)$, hemoglobin $(\mathrm{P}=0.0026)$ and a near significant result for calcium $(\mathrm{P}=$ 0.0931) (Fig. 2). The directions of the effect of each variable remained the same as seen in the single variable models. In short, patients hailing from counties with low socioeconomic status had higher rates of progression to dialysis or death and hypoalbuminema, anemia, hyperparathyroidism and hypocalemia all independently correlated with reduced survival and more rapid progression to dialysis-dependence $(\mathrm{P}<0.0001)$ (Fig. 2).

\section{Discussion}

Projections that the ESRD population will exceed 784,000 patients by the year 2020 [4] underscore the need to address non-traditional and/or secondary risk factors for CKD, alone a public health problem of growing magnitude. In north central West Virginia, CKD patients are predominantly white, often hypoalbuminemic and diabetic; most resided in counties with low socioeconomic standing. Hypoalbuminemia was independently associated with increased rates of progression to dialysis or death as was anemia, hyperparathyroidism or hypocalemia. Patients hailing from counties with low socioeconomic status also had higher rates of progression to dialysis or death.

A predominantly rural state of 1.8 million people, West Virginia is the only state with all 55 of its counties in the confines of Appalachia. Appalachia, a term used to describe a cultural region in the eastern United States that stretches from the southern tier of New York state to northern Alabama, Mississippi, and Georgia, includes West Virginia, Pennsylvania, Ohio, Maryland, Kentucky, Virginia, North Carolina, Tennessee and South Carolina. The population in some areas of Appalachia such as West Virginia is aging, due in part to outmigration of young people and lower rates of immigrant migration to the region in the last half of the 20th century $[12,13]$. Indeed, the highest age adjusted incidence rates of dialysis have occurred in the Mississippi Basin and through the Ohio Valley, an area encompassing most of Appalachia $[12,13]$. Despite the increasingly older population in West Virginia, the proportion of patients older than 65 was less than half of the overall group and greater than half only in patients with Stage 4 CKD (Table 1). West Virginians, and in particular, West Virginia women, have shorter life expec- tancies than the national average with southern West Virginia having some of the lowest in the nation $[10,11]$. Only 4 counties in West Virginia have life expectancies exceeding the national mean and life expectancies are reportedly on the decline in some West Virginia counties [10, 11].

Historically, the Appalachian region has been medically under-served, and rates of poverty, obesity, tobacco use, and limited educational attainment exceed those of other states $[12,13]$. Socioeconomically, the state ranks well below the nation with higher percentages of West Virginians living below the federal poverty level $(\%<$ FPL) $(17.4 \%$ vs. $13.2 \%$, respectively) and hailing from counties with lower median household incomes than national levels (\$37,528 vs. $\$ 52,029$, respectively) $[5,6]$. West Virginia's physician population is clustered in the least rural areas, requiring patients to travel long distances for specialty physician care. Those without the social or economic means to travel often present for care well past the period when medical intervention could provide benefit. Thus, geographic distance from health care may be a contributing factor, though the high incident rate of non-diabetic ESRD among West Virginians remains largely unexplained. Studies associating CKD with poverty in the US largely invoke race as a contributing factor with African Americans and other ethnic minorities generally faring worse than whites, particularly when of lower affluence [14-21]. As reflected in our CKD cohort, a high proportion of West Virginia's population is non-Hispanic white $(93.5 \%$ vs $65.6 \%$ for US) with a low prevalence of African Americans $(3.6 \%$ vs $12.8 \%$ for US) $[5,6]$. West Virginia's racially homogeneous population and the CKD population described herein contrast greatly with other CKD studies where between 28 and $51 \%$ of individuals were found to be white $[8,9]$. The paucity of African Americans in West Virginia and in our CKD patient population in particular precludes speculations related to racial disparities, however, suggests an impact of other factors on progression that is not limited to racial or ethnic minorities.

A link between poverty and malnutrition might be postulated by the high prevalence of hypoalbuminemic CKD patients living in socioecononomically disadvantaged counties. Indeed, rural households in the US are particularly vulnerable to food security and food insecurity $[22,23]$ has been associated with low quality diets in the Mississippi delta [24]. Anecdotal reports of the so-called Appalachian diet (high in carbohydrates, fat and prepared foods) are in keeping with surveys reporting comparatively low consumption of fruits and vegetables when compared to other states, as well as the high prevalence of obesity in West Virginia [3]. Diets high in saturated fats were highly prevalent in West Virginia children, 42 percent of whom were at the 85 th percentile for body mass index [25]. Among NHANES participants, energy and nutrient intakes of adults from families considered food insufficient were found to be lower than those of their food sufficient counterparts [26]. Compared to those from 
food-sufficient families, adults from food-insufficient families had lower serum albumin levels and were more likely to have serum albumin $<3.5 \mathrm{~g} / \mathrm{dl}[26]$.

A consequence of altered albumin homeostasis, low serum albumin is a marker of malnutrition and chronic inflammation. Protein malnutrition is considered of minor importance as a contributor to the low albumin levels seen in ESRD, a stance supported by the lack of effectiveness of nutritional supplements in normalizing serum albumin. In ESRD, inflammation is thought to be primary, causing a decline in the rate of albumin synthesis with hypoalbuminemia being a manifestation, rather than a direct result of disease. Despite a move toward earlier recognition and initiation of dialysis mean serum albumin levels of incident dialysis patients declined significantly over time between 1996 and 2004 [27, 28]. Mean albumin levels of incident dialysis patients of $3.1-3.2 \mathrm{~g} / \mathrm{dl}$ reported within the last decade are in keeping with those among advanced CKD patients from a large integrated healthcare system, nearly $1 / 4$ of whom had an albumin level below $3.5 \mathrm{~g} / \mathrm{dl}$ as well as our late stage West Virginia patient, where this prevalence was $62 \%$ [8]. In our patients, a low serum albumin at first presentation was not uncommon and compared to the NHANES III population, members of a large health care system and a cohort of CKD patients considered urban poor, West Virginia CKD patients had significantly greater prevalence of hypoalbuminemia at every level of renal function $[8,9]$.

While the relative contributions of chronic inflammation and malnutrition to low serum albumin are not well delineated in earlier stages of CKD, the high rate of hypoalbuminemia among incident dialysis patients suggests that such drivers of hypoalbuminemia are operative in earlier stages of CKD, long before patients reach dialysis-dependence. Others have reported an independent relationship between all-cause mortality and serum albumin level in patients with moderate to severely advanced CKD [29]. These observations suggest a predictive role for a low serum albumin and further suggest that the potential role of a deficient nutritional intake, in addition to that of chronic inflammation, is worthy of further study. The complexities are reflected in a recent model developed and validated for estimating progression of CKD, which utilizes albumin and a number of other clinical and biochemical parameters [30].

In reviewing and analyzing our data, the following limitations are recognized. First, because of logistic difficulties associated with retrieval of blood and urine lab results, not all lab data was included for every patient nor were urine studies or weights available. Lab data for patients whose blood was drawn locally at a non-university-affiliated lab was communicated by telefax to our office where it was manually entered into our electronic medical record and thus amalgamated with any lab work done on site. Second, transplanted patients who did not reach either end point of death or dialysis are included as CKD patients by their stage of
CKD. Third, socioeconomic data is by county level only and not based on individual patient account. Thus, our analyses are based on county of residence for a given patient and not a patient's individual socioeconomic status. Fourth, as noted above, because socioeconomic status is not known on a patient level, no direct correlations between socioeconomic and clinical factors can be made. Fifth, the racial homogeneity of our predominantly Caucasian patient population precludes conclusions involving the impact of other racial or ethnic groups. Sixth, markers of chronic inflammation were not measured, thus their contribution to the hypoalbuminemic state in these patients limits our conclusions as to the etiology of hypoalbuminemia in our patients.

Pathogenetic factors related to progressive disease notwithstanding, we suggest that poverty and culture are key factors in the development of risk and progression of CKD and may trump race as a risk factor. The high prevalence of CKD, coupled with the high incidence of ESRD in this predominantly Caucasian state underscore the need to focus on poverty, irrespective of race or ethnicity.

\section{Acknowledgements}

The authors gratefully acknowledge Susan Rodman for her invaluable assistance with database development, and Janet Boord, Margaret Favro, and Katelyn Carter for countless hours of data entry.

\section{References}

1. Snyder JJ, Foley RN, Collins AJ. Prevalence of CKD in the United States: a sensitivity analysis using the National Health and Nutrition Examination Survey (NHANES) 1999-2004. Am J Kidney Dis. 2009;53(2):218-228.

2. US Renal Data System. USRDS 2009 Annual Data Report: Atlas of End-Stage Renal Disease in the United States, National Institutes of Health, National Institute of Diabetes and Digestive and Kidney Diseases. Bethesda, MD, 2009.

3. Centers for Disease Control and Prevention (CDC). Behavioral Risk Factor Surveillance System Survey Data, Atlanta, GA. U.S. Department of Health and Human Services, Centers for Disease Control and Prevention. 2005-2009.

4. Gilbertson DT, Liu J, Xue JL, Louis TA, Solid CA, Ebben JP, Collins AJ. Projecting the number of patients with end-stage renal disease in the United States to the year 2015. J Am Soc Nephrol. 2005;16(12):3736-3741.

5. U.S. Census Bureau. State and County QuickFacts. Data Profile, West Virginia, 2009. http://quickfacts.census. gov/qfd/states/54000.html.

6. U.S. Census Bureau: Small Area Income and Poverty 
Estimates, Data Profile, West Virginia compared to United States of America, 2008. http://www.census.gov/did/ www/saipe/data/statecounty/data/2008.html.

7. National Center for Health Statistics. National Health and Nutrition Examination Survey (NHANES) Analytic Guidelines. http://222.cdc.gov/nchs/nhanes/nhanes2003-2004/ analytical guidelines.htm.

8. Go AS, Chertow GM, Fan D, McCulloch CE, Hsu CY. Chronic kidney disease and the risks of death, cardiovascular events, and hospitalization. $\mathrm{N}$ Engl J Med. 2004;351(13):1296-1305.

9. Hall YN, Choi AI, Chertow GM, Bindman AB. Chronic kidney disease in the urban poor. Clin J Am Soc Nephrol. 2010;5(5):828-835.

10. West Virginians for Affordable Health Care. Early Deaths: West Virginians Have Some of the Shortest Life Expectancies in the United States, Issue Brief; November, 2008. www.wvahc.org Accessed November 2010.

11. Ezzati M, Friedman AB, Kulkarni SC, Murray CJ. The reversal of fortunes: trends in county mortality and cross-county mortality disparities in the United States. PLoS Med. 2008;5(4):e66.

12. Appalachian Regional Commission. The Appalachian Region. http://www.arc.gov/appalachian_region/TheAppalachianRegion.asp. Accessed November 29, 2010.

13. Appalachian Regional Commission. The Appalachian Commission: The Aging of Appalachia http://aging.senate.gov/award/arc1.pdf. Accessed November 29, 2010.

14. Mehrotra R, Kermah D, Fried L, Adler S, Norris K. Racial differences in mortality among those with CKD. J Am Soc Nephrol. 2008;19(7):1403-1410.

15. Norris K, Nissenson AR. Race, gender, and socioeconomic disparities in CKD in the United States. J Am Soc Nephrol. 2008;19(7):1261-1270.

16. Hossain MP, Goyder EC, Rigby JE, El Nahas M. CKD and poverty: a growing global challenge. Am J Kidney Dis. 2009;53(1):166-174.

17. Norris K, Mehrotra R, Nissenson AR. Racial differences in mortality and ESRD. Am J Kidney Dis. 2008;52(2):205-208

18. Young BA. The interaction of race, poverty, and CKD. Am J Kidney Dis. 2010;55(6):977-980.

19. Crews DC, Charles RF, Evans MK, Zonderman AB, Powe NR. Poverty, race, and CKD in a racially and socioeconomically diverse urban population. Am J Kidney Dis. 2010;55(6):992-1000.

20. Volkova N, McClellan W, Klein M, Flanders D, Klein- baum D, Soucie JM, Presley R. Neighborhood poverty and racial differences in ESRD incidence. J Am Soc Nephrol. 2008;19(2):356-364.

21. Wesson DE. Is the ethnic disparity in CKD a symptom of dysfunctional primary care in the US? J Am Soc Nephrol. 2008;19(7):1249-1251.

22. Walker JL, Holben DH, Kropf ML, Holcomb JP, Jr., Anderson H. Household food insecurity is inversely associated with social capital and health in females from special supplemental nutrition program for women, infants, and children households in Appalachian Ohio. J Am Diet Assoc. 2007;107(11):1989-1993.

23. Nord M, Andrews M, Carlson S: Measuring Food Security in the United States. Household Food Security in the United States, 2007.

24. Champagne CM, Casey PH, Connell CL, Stuff JE, Gossett JM, Harsha DW, McCabe-Sellers B, et al. Poverty and food intake in rural America: diet quality is lower in food insecure adults in the Mississippi Delta. J Am Diet Assoc. 2007;107(11):1886-1894.

25. Gonzales EN, Marshall JA, Heimendinger J, Crane LA, Neal WA. Home and eating environments are associated with saturated fat intake in children in rural West Virginia. J Am Diet Assoc. 2002;102(5):657-663.

26. Dixon LB, Winkleby MA, Radimer KL. Dietary intakes and serum nutrients differ between adults from foodinsufficient and food-sufficient families: Third National Health and Nutrition Examination Survey, 1988-1994. J Nutr. 2001;131(4):1232-1246.

27. US Renal Data System, USRDS 2009 Annual Data Report. Atlas of End-Stage Renal Disease in the United States, National Institutes of Health, National Institute of Diabetes and Digestive and Kidney Diseases, Bethesda, MD, 2006.

28. Kaysen GA, Johansen KL, Cheng SC, Jin C, Chertow GM. Trends and outcomes associated with serum albumin concentration among incident dialysis patients in the United States. J Ren Nutr. 2008;18(4):323-331.

29. Menon V, Greene T, Wang X, Pereira AA, Marcovina SM, Beck GJ, Kusek JW, et al. C-reactive protein and albumin as predictors of all-cause and cardiovascular mortality in chronic kidney disease. Kidney Int. 2005;68(2):766-772.

30. Tangri N, Stevens LA, Griffith J, Tighiouart H, Djurdjev O, Naimark D, Levin A, et al. A predictive model for progression of chronic kidney disease to kidney failure. JAMA. 2011;305(15):1553-1559. 